\title{
Effect of Hot Rolling on the Intrinsic Properties of Aluminium- Titanium Bonded by PTFE/ C -Cyanoacrylate
}

\author{
Mahmoud A. Rabah 1,*
}

${ }^{1}$ Chemical and electrochemical treatments lab., Mineral Processing Dept, Central Metallurgical research and development Institute (CMRDI), 11421 El-Tebbin, Helwan, Cairo, Egypt

*Corresponding author email: mrabah010@gmail.com; mahmoudrabah2@hotmail.com

DOI: https://doi.org/10.34256/irjmt2133

Received: 23-03-2021, Accepted: 06-04-2021, Published: 10-04-2021

Abstract: The concern of this study shows the effect of hot rolling on the properties of a composite sheet prepared from aluminium bonded to titanium metals sandwiching PTFE (Du Pont)/graphite emulsion in perfluoro kerosene. The metals were soaked in hot oxygenated water and dried at $80^{\circ} \mathrm{C}$ for $5-10$ minutes to create a thin film of oxide. The metals were bonded with cyanoacrylate blended to the polymer emulsion that applied to the oxidized surface of the clean metals. Two coated surfaces sandwich the polytetrafluoroethylene (PTFE)/graphite emulsion followed by hot-rolling. The rolling process was matched at $500-560{ }^{\circ} \mathrm{C}\left(\approx 150{ }^{\circ} \mathrm{C}\right.$, over the melting point of the PTFE $)$ under a pressure of $150-200 \mathrm{KPa}$. The obtained composite sheet was annealed at $550{ }^{\circ} \mathrm{C}$ to remove any residual stresses. Results revealed that upon cooling, the mix microphase would separate with the $\mathrm{OH}$ radicals on the metal surface and the CF displaced away. The temperature and time of cyanoacrylate application enhanced the extent of adhesion to create a homogeneous composite metal sheet. The effect of the hot rolling conditions was ascribed to the PTFE underactivity and incompatibility. Rolling imparts squeezing of the metals and changes the intrinsic properties. Linear thermal expansion coefficient of the composite sheet confirms partial diffusion of the soft metal in the harder one across the adhesive. The applied technique deforms the PTFE particles without inhibiting the adhesion strength of the cyanoacrylate. The prepared sheet has physical properties that would be suitable for bailiwick and structural application.

Keywords: Al-Ti PTFE bonded laminar sheet, aeronautic sheet, PTFE as adhesive material

\section{Introduction}

The region materials to be used is also a gift in nature and won't to producing the first aircraft. Aerospace materials square measure developed metal alloys used for region applications or have returned to distinguished [1]. Materials engineering is rigid and a vital norm among the region application has been total. The international customary bodies maintain specifications for the materials and processes involved [2]. Engineers and academicians had performed intensive work for aeronautical materials improvement. The region materials to be used is also a gift in nature and won't to producing the early craft. Such materials were conjointly used once timber in wing structures and material and dope to cover them. the fabric quality was of utmost importance so the timber would be of fastidiously customary specifications was this extremely needed for the right choice, manufacture, and use of these materials. Specifications were then developed and updated with the cooperation of manufacturer's engineers or even government technicians and sometimes with the help of university engineering departments.

Development of materials to be used within the region application was to adopt materials like means that, hardening of aluminium alloy(s) and evaluation of this goal. Several of those new materials and how to process the most effective use of them are reportable. The monetary and technical facilities and/or supervision of national laboratories and analysis establishments counselled aluminum or aluminum alloys for airframes, skin, and composites for structures. Some reporters expected that composite materials of aluminium metal could represent the roost once it involves region innovation and similar updated structures [3]. Altogether, patriarch et al [4] reportable the mechanical properties and fracture of $\mathrm{Al}-15$ pastry primarily based metal matrix composites. it had been comparatively low value, particularly in comparison to aluminium or composites of aluminium alloys. The aluminum producer Co, Alcoa, in 2013, for instance, expected that around 6 June 1944 additional aluminum can be 
employed in planes compared to 2011. the corporate, conjointly claimed that the present fleet of airliners and military jets square measure the most users of aluminum, and newer styles still specify countless this metal. It was reportable that one in every of the biggest traveler airliners within the world, contains ten times the number used as compared to the less updated model of the plane. Also, Boeing's 787 Dreamliner, is structured containing two-hundredth aluminum alloy 7085 (by weight), that was comparatively new [5].

Aluminium is alloyed with some nonferrous components like $\mathrm{Mn}$, silicon, aluminium, magnesium, or metallic element and metallic element to any increase its strength. Cold operating could be a technique won't to increase the strength of those alloys. However, some alloys square measure any strong and hardened by heat treatment. Aluminium matrix composites: (MMCs) encompass metal alloys bolstered with fibers, whiskers, particulates, or wires. Alloys used as matrices thus far a square measure of aluminium-boron and Al-Mg. for instance, and in keeping with NASA space vehicle, 240 struts were fabricated from aluminium bolstered with $B$ fiber. The investigator reportable the influence of some alloying components on the microstructures and mechanical properties of aluminium alloys and aluminium alloy composites [6]. once oxidized, aluminium forms a hard, microscopic compound protecting coating from the atmosphere. $\mathrm{Al}-\mathrm{Zn}$ alloy 7075 is robust as compared to steel. The alloy includes five.6-6.1\% zinc, $2.1-2.5 \%$ atomic number 12 , and $1.2-1.6 \%$ aluminum. it's in heat temper grade $[7,8]$. With the correct choice and placement of carbon fibers, the composites of aluminium will be stronger and stiffer than steel elements with similar thicknesses of forty to seventieth. The chemical resistance is far higher than that of glass-reinforced composites. significantly alkalescent medium. However, carbon composites square measure comparatively brittle. they need no yield behaviour and their resistance to impact is low [9]. Thermal characteristics of carbon fibers disagree as compared to the alternative. This property helps in creating the planning of structures with zero or low linear and coplanar enlargement [10]. There square measure many varieties of aluminium adhesives with numerous cure mechanisms. Single part epoxy aluminium adhesives cure with heat to make high strength bonding. Permabond offers many grades which square measure colour matched to aluminium to look like fastening or brazing.[11].

Amigo et, al reportable atomic number 22 and aluminium composites materials were bolstered by TiAl compounds [12]. The authors are reportable that numerous authors have studied microstructure/mechanical property relationships for discontinuously bolstered aluminium. The results of the reinforcements on the mechanical properties of the aluminium alloys square measure generally helpful whereas atomic number 22 and its alloys stand out primarily to their specific strength and glorious corrosion resistance. Rajakumar [13] showed that the most important issue once the change of integrity commercially pure atomic number 22 (Ti) and aluminium (Al) lies in the existence of the formation of compound films and brittle intermetallic within the bond region. The diffusion bonding (DB) method parameters like bonding temperature, bonding pressure, and holding time play a major role to see the joint strength.

Cao et. al [14] studied the influences of interface morphology, diffusion layer and reaction product, constraint effect on the mechanical properties of the laminar metals composites (LMCs). The detailed conclusions were reported as follows:

1. The increase of hot-pressing temperature changes the morphologies of $\mathrm{Ti} / \mathrm{Al}$ interface to the waveform, and the intermetallic phases don't change. The width of the intermetallic phases layer at $\mathrm{Mg} / \mathrm{Al}$ interface increases significantly with the increasing temperature.

2. The increase of hot-pressing temperature, both bonding strength and hardness of Ti/Al interface increase and the maximum bonding strength is obtained at $400{ }^{\circ} \mathrm{C}$.

3. The increase of temperature, UTS of LMCs increases at the expense of FE propagation.

Zhang et al., [15] reported that with increasing temperature, the thickness in layer diffusion increased and the mechanical properties of LMCs improved.

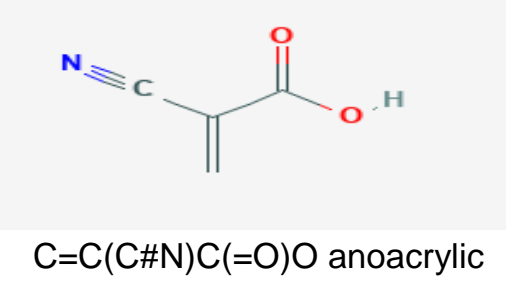

This paper has its aim to check the impact of $\mathrm{pH}$ on the steadiness of bonded aluminium-titanium metals sandwiched with PTFE/graphite replacing the insert moulding technique. The composite metal sheet of $\mathrm{Al}$ blended in perfluoro kerosene and adhered by cyanoacrylate adhesive. The impact of the roll bonding temperature on the intrinsic properties of $\mathrm{Al}$-titanium sandwiching PTFE/graphite using cyanoacrylate adhesive was studied.

\section{Experimental}

\subsection{Materials and Method}

The polymer tetrafluoroethylene was the product of Du point, Danisco Egypt Trading Co., New Cairo. 
The perfluoro kerosene adhesive (2-Methyl-2butene) was supplied by Merck. A polymer PTFE sample weighing $10 \mathrm{~g}$ was dissolved in $100 \mathrm{ml}$ perfluoro kerosene-L having the chemical formula $\mathrm{C}_{5} \mathrm{H}_{10}$, and doped with synthetic aluminum hydroxide (5wt \%). A similar quantity of flake graphite fine powder $(<10 \mathrm{um}$ ) was added to form an emulsion for the power spraying on the clean surface of aluminium and titanium sheets.

The following Table 1 gives the characteristics of the PTFE and perfluoro-kerosene.

Synthetic $\mathrm{Al}(\mathrm{OH})_{3}$ was prepared by dissolving Al metal in $3 \mathrm{M} \mathrm{HCl}$ and filtered. The obtained $\mathrm{AlCl}_{3}$ was treated with ammonia to give gelatinous $\mathrm{Al}(\mathrm{OH})_{3}$ at a pH value of 8 .

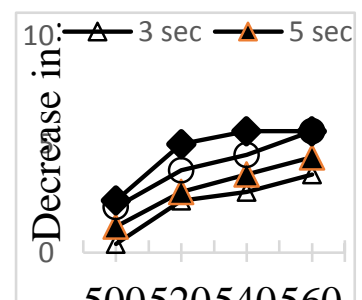

500520540560

Temperatur... thickness as affected bt temperature

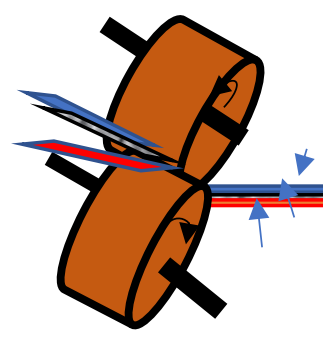

hot roll bonding

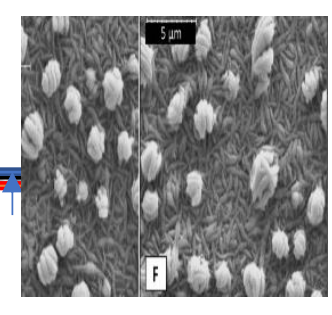

Al nanoparticles

Properties of the used graphite

$>$ It has a high melting point, similar to that of diamond.

$>$ has a soft, slippery feel, and is used in pencils and as a dry lubricant for things like locks. ...

$>$ has a low density $\left(2.15-2.20 \mathrm{~kg} / \mathrm{d} . \mathrm{cm}^{3}\right)$

$>$ is insoluble in water and organic solvents.

Table 2 shows the thermal properties of the used graphite

\subsection{The chemicals used}

$>$ Table 3 shows the properties of the chemicals used.

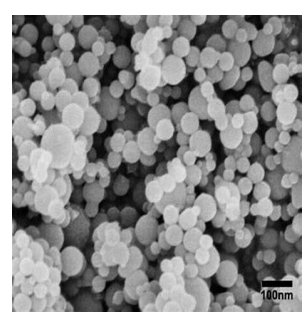

PTFE particles

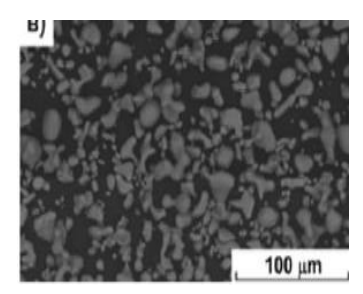

TEM of titanium

Figure 1. The graphical abstract

Table 1 The characteristics of the PTFE and perfluoro-kerosene

\begin{tabular}{|c|c|c|c|}
\hline Property & ASTM method & init & PTFE Granular Resin \\
\hline Tensile strength, $23^{\circ} \mathrm{C}$ & D4894/4895 & MPa )psi) & 31 \\
\hline Elongation, $23^{\circ} \mathrm{C}$ & D4894/4895 & $\%$ & 400 \\
\hline Hardness durometer & D 2240 & Shore D & 55 \\
\hline Volume resistivity & D 257 & Ohm's & $>10^{18}$ \\
\hline Surface resistivity & D 257 & Ohm's & $>10^{18}$ \\
\hline \multicolumn{4}{|l|}{ Perfluoro-kerosene } \\
\hline Boiling point & ${ }^{\circ} \mathrm{C}$ & $70-240$ & \\
\hline Density & $\mathrm{g} / \mathrm{mL}$ at $25^{\circ} \mathrm{C}$ & 1.94 & \\
\hline Refractive index & $n 20 / D$ & Lit. & \\
\hline $\begin{array}{l}\text { Flash point } \\
\text { Linear thermal expansion coefficient }\end{array}$ & ${ }^{\circ} \mathrm{F}$ & $\begin{array}{c}115 \\
\left(10^{-6} \mathrm{~m} /\left(\mathrm{m}^{\circ} \mathrm{C}\right)\right)\end{array}$ & 7. $4 \sim 27$ \\
\hline
\end{tabular}


Table 2 The thermal properties of the used graphite

\begin{tabular}{|l|l|l|l|l|l|}
\hline \multicolumn{1}{|c|}{ properties } & \multicolumn{1}{|c|}{ T68 } & \multicolumn{1}{c|}{ Unit } & Tole Tolerance $\mathrm{r}$ & \multicolumn{1}{c|}{ Test Method } \\
\hline Thermal Conductivity & XY axis & 1500 & $\mathrm{~W} / \mathrm{mK}$ & \pm 100 & AC calorimeter \\
\cline { 2 - 6 } & Z axis & 5 & $\mathrm{~W} / \mathrm{mK}$ & \pm 0.5 & Laser flash \\
\hline Color & Black & - & - & Visual \\
\hline Thermal Diffusivity & 8.5 & $\mathrm{~cm}^{2} / \mathrm{S}$ & \pm 0.5 & AC calorimeter \\
\hline Density & 2.1 & $\mathrm{~g} / \mathrm{cm}^{3}$ & \pm 0.1 & Archimedes law \\
\hline Electrical Conductivity & $>13000$ & $\mathrm{~S} / \mathrm{cm}$ & - & JIS K7194 \\
\hline Flexural Strength & 10000 & times & - & - \\
\hline Working Temperature & $-40 \sim 400$ & ${ }^{\circ} \mathrm{C}$ & - & AC calorimeter \\
\hline $\begin{array}{l}\text { Heat Capacity (HC) } \\
\text { Linear thermal expansion coefficient }\end{array}$ & $\begin{array}{l}0.895 \\
\text { 4-8 }\end{array}$ & $\begin{array}{l}\mathrm{J} / \mathrm{g}-\mathrm{K} \\
(\mathrm{c}))\end{array}$ & - & - \\
\hline
\end{tabular}

Table 3 Properties of the chemicals

\begin{tabular}{|c|c|c|c|}
\hline chemical & Source & Purpose & Property \\
\hline $\begin{array}{l}\text { Nitric acid } \\
\mathrm{H}_{2} \mathrm{SO}_{4} \\
\mathrm{HCl}\end{array}$ & $\begin{array}{l}\text { SP.GR.1.18 (AR) } \\
\text { Min. assay } 36 \% \\
\text { Fuming } 69 \% \\
\mathrm{H}_{2} \mathrm{SO}_{4} \quad 95-97 \% \\
\text { Extra pure } \\
\text { SP.GR.1.18 (AR) }\end{array}$ & $\begin{array}{l}\text { Leaching } \\
\text { Process }\end{array}$ & $\begin{array}{l}\text { ADWIC } \\
\text { Riedel- de Hein } \\
\text { ADWIC }\end{array}$ \\
\hline $\begin{array}{l}\mathrm{Ca} \mathrm{CO}_{3} \\
\text { EJSF2 } \\
\text { Ca oxide }\end{array}$ & $\begin{array}{l}\text { Green Egypt } \\
\text { Sigma Aldrich }\end{array}$ & Synthesis process & $\begin{array}{l}99.3, \\
1.6 \mathrm{um} \\
3.34 \mathrm{~g} / \mathrm{cm}^{3}, 1.57 \mathrm{um}\end{array}$ \\
\hline $\begin{array}{l}\mathrm{NaOH} \\
\text { Ammonium hydroxide }\end{array}$ & $\begin{array}{l}\text { United Co. } \\
\text { for chemicals \& Med. } \\
\text { Preparations }\end{array}$ & & $\begin{array}{l}\text { reagent for analysis } \\
25 \% \text { Pure reagent for } \\
\text { analysis }\end{array}$ \\
\hline $\mathrm{AgNO}_{3}$ (Silver Nitrate) & & Chloride ion determination & $\begin{array}{l}\text { Pure reagent for } \\
\text { analysis }\end{array}$ \\
\hline distilled water & & Chemical reactions & \\
\hline Tap water & & Other purposes & \\
\hline
\end{tabular}
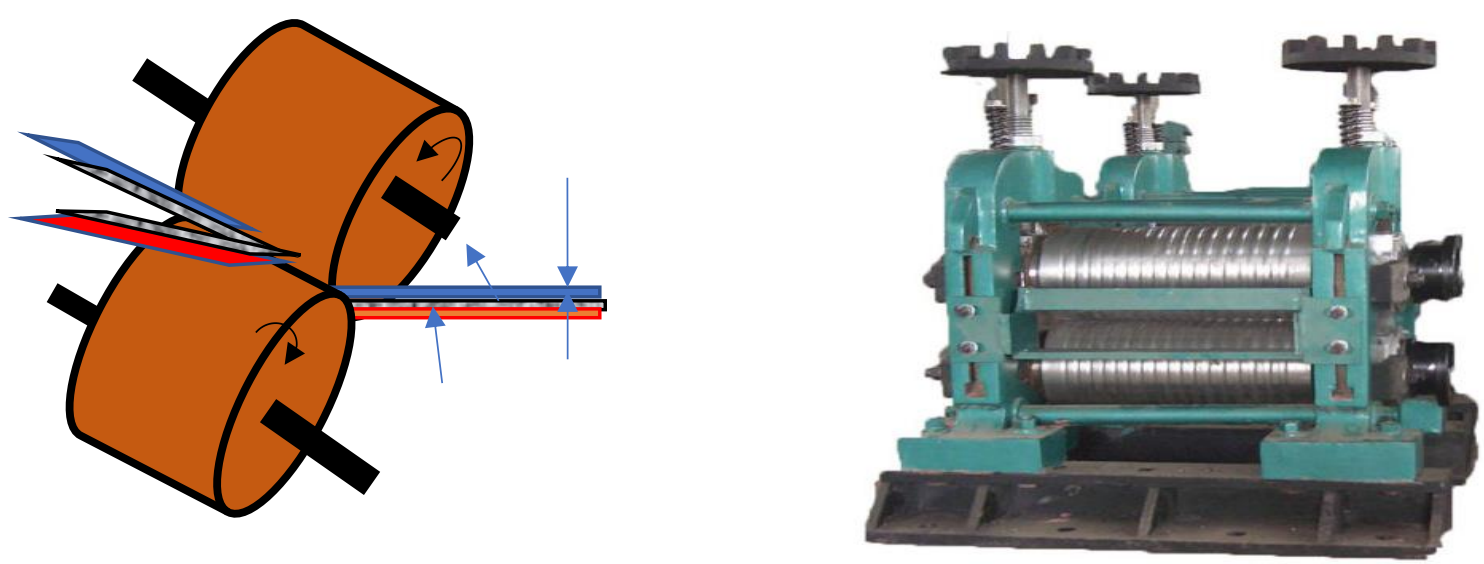
Figure 2a Assembly of the Bonding device

Figure $2 b$ Photograph of the double roller machine

Table 4 Summary of the composition of the prepared samples

\begin{tabular}{|c|c|c|c|c|c|c|c|c|}
\hline \multirow[t]{2}{*}{ Sample \# } & \multicolumn{4}{|c|}{ Thickness, um } & \multirow{2}{*}{$\begin{array}{c}\text { Hypothetical } \\
\text { total thickness, } \\
\text { um }\end{array}$} & \multirow{2}{*}{$\begin{array}{c}\text { Al: } \mathrm{Ti} \\
\text { mass ratio }\end{array}$} & \multicolumn{2}{|c|}{ Bonding, } \\
\hline & $\overline{\mathrm{Al}}$ & $\mathrm{Ti}$ & PTFE & adhesive & & & $\mathrm{T},{ }^{\circ} \mathrm{C}$ & t, sec. \\
\hline 1 & 100 & 50 & 100 & 1 & 251 & 1.16 & 500 & 3 \\
\hline 2 & 100 & 75 & 100 & 1 & 276 & 0.77 & 550 & 5 \\
\hline 3 & 100 & 100 & 100 & 1 & 301 & 0.58 & 600 & 8 \\
\hline 4 & 200 & 100 & 50 & 1 & 351 & 1.16 & 500 & 3 \\
\hline 5 & 200 & 100 & 100 & 1 & 401 & 1.16 & 600 & 5 \\
\hline 6 & 200 & 200 & 100 & 1 & 501 & 0.58 & 500 & 8 \\
\hline 7 & 300 & 200 & 100 & 1 & 601 & 1.74 & 600 & 5 \\
\hline 8 & 250 & 200 & 150 & 2 & 602 & 1.45 & 500 & 8 \\
\hline 9 & 250 & 250 & 150 & 2 & 652 & 0.77 & 550 & 5 \\
\hline 10 & 250 & 250 & 200 & 2 & 702 & 0.77 & 600 & 8 \\
\hline
\end{tabular}

Table 5 The percent decrease in thickness of the triple sheet upon bonding Al: Ti and PTFE/C

\begin{tabular}{|l|l|l|l|l|l|l|l|l|l|}
\hline & $\begin{array}{l}\Sigma 5-20 \\
\text { sec. }\end{array}$ & $\begin{array}{l}\sum 20-40 \\
\text { Sec. }\end{array}$ & $\sum 4060 \backslash$ sec. & $\begin{array}{l}\sum 5-20 \\
\text { sec. }\end{array}$ & $\begin{array}{l}\sum 20-40 \\
\text { sec. }\end{array}$ & $\begin{array}{l}\sum 40-60 \\
\text { sec. }\end{array}$ & $\begin{array}{l}\sum 0-20 \\
\text { sec. }\end{array}$ & $\begin{array}{l}\Sigma 0-40 \backslash \\
\text { sec. }\end{array}$ & $\begin{array}{l}\Sigma 0-60 \\
\text { sec. }\end{array}$ \\
\hline 1 & 0.8 & 0.45 & 0.3 & 0.76 & 0.66 & 0.50 & 1.56 & 1.91 & 2.41 \\
\hline 2 & 0.68 & 0.41 & 0.28 & 0.60 & 0.36 & 0.30 & 1.104 & 0.77 & 2.085 \\
\hline 3 & 0.51 & 0.28 & 0.24 & 0.80 & 0.28 & 0.211 & 1.310 & 0.56 & 2.081 \\
\hline 4 & 0.80 & 0.448 & 0.388 & 0.60 & 0.65 & 0.211 & 1.310 & 0.56 & 2.842 \\
\hline 5 & 0.83 & 0.482 & 0.396 & 0.75 & 0.58 & 0.303 & 1.58 & 1.082 & 2.965 \\
\hline 6 & 0.85 & 0.490 & 0.405 & 0.37 & 0.38 & 0.188 & 1.22 & 0.870 & 2.278 \\
\hline 7 & 0.86 & 0.492 & 0.416 & 0.424 & 0.454 & 0.222 & 1.264 & 0.870 & 2.356 \\
\hline 8 & 0.76 & 0.475 & 0.400 & 0.360 & 0.620 & 0.260 & 1.120 & 1.095 & 2.475 \\
\hline 9 & 0.54 & 0.408 & 0.346 & 0.214 & 0.310 & 0.170 & 0.754 & 0.718 & 1.642 \\
\hline 1 & 0.54 & 0.412 & 0.352 & 0.196 & 0.298 & 0.736 & 0.736 & 0.710 & 1.626 \\
\hline
\end{tabular}

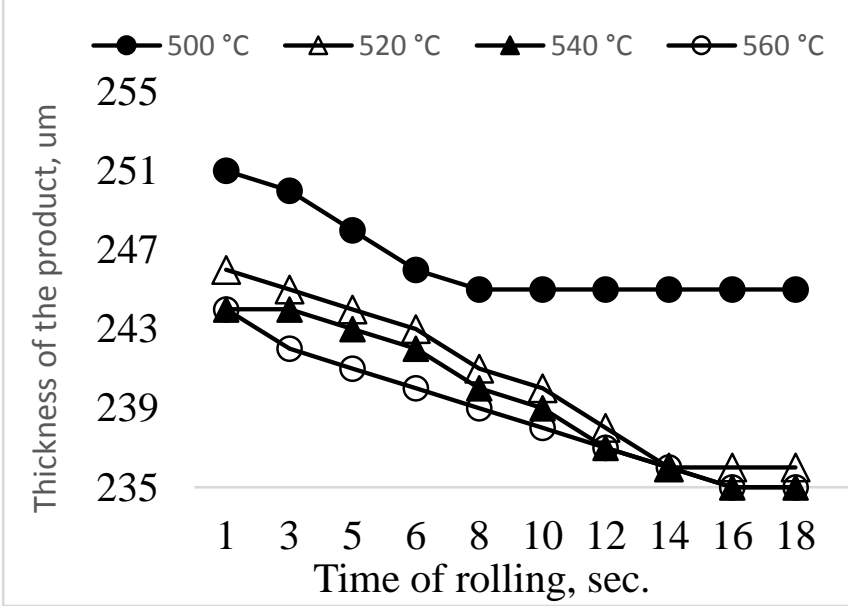

Figure 3. Effect of time of rolling on the thickness of the triple layered sheet \# 1 at temperatures up to $560{ }^{\circ} \mathrm{C}$. 


\section{Results}

Fig. 1 shows the graphical abstract of this manuscript. It contains the SEM image of the aluminium metal and the PTFE. A schematic diagram of the double roller for the preparation of the triple layered sheet by mechanical bonding method. The graphical abstract also contains a figure of the effect of temperature on the TLMC thickness. Fig. 2a,b shows an assembly of the rolling device (2a) and a photograph of the double roller ${ }^{*}$ Fig. $2 b$ ).

Figure. 3 shows the effect of the rolling time on the thickness of sample \#1 at temperatures up to 560 ${ }^{\circ} \mathrm{C}$ It is seen that at $500{ }^{\circ} \mathrm{C}$, the increase in bonding time up to 40 seconds causes a corresponding decrease in the thickness after which more increase in time of bonding becomes immaterial. For one and the same bonding time, increasing the bonding temperature causes a further decrease in the thickness of the prepared samples.

Fig. 4a shows that a linear relation holds the rolling time and the percent decrease in the thickness of the prepared TLMC samples. Fig. $4 \mathrm{~b}$ checks the effect of temperature on the thickness of sample \#1 upon hot rolling. It is seen that the increase in the rolling temperature causes a decrease in the thickness. The effect becomes more significant with increase in rolling time up to $60 \mathrm{sec}$.

Fig. 5a shows the effect of $\mathrm{Al}$ : Ti mass ratio on the magnitude of thickness of the rolled triple sheet at $550{ }^{\circ} \mathrm{C}$ for $40 \mathrm{sec}$. It is seen that the thickness decreases regularly from 0.65 um with $1.74 \mathrm{Al}: \mathrm{Ti}$ to 0.38 um with $0.58 \mathrm{Al}: \mathrm{Ti}$ mass ratio. Fig. $5 \mathrm{~b}$ shows the effect of sample composition on the thickness magnitude of the bonded samples as a function of rolling time at $5-20 \mathrm{sec}$., $20-40 \mathrm{sec}$. and $50-60 \mathrm{sec}$. It is seen that the thickness of the sample decreases with the increase in the titanium metal and decreases with higher rollinging time.
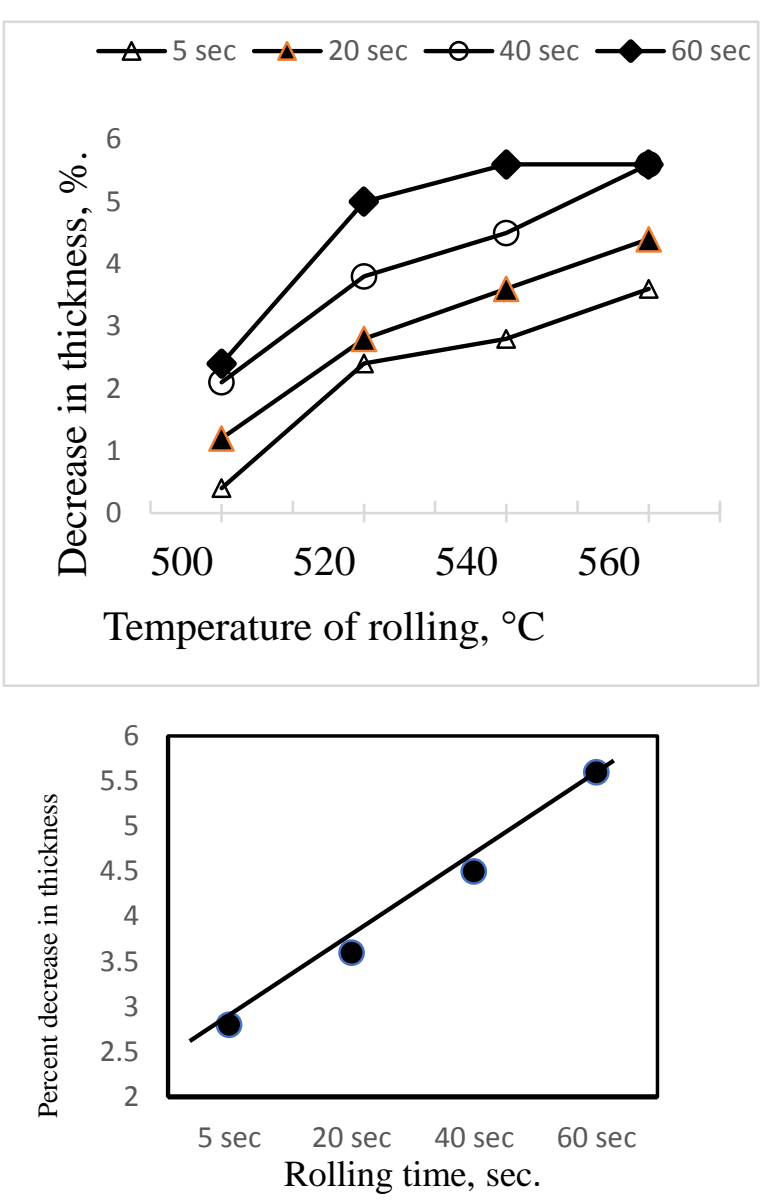

Fig 4a Effect of rolling time on percent decrease in thickness of the $\mathrm{Al}$ : Ti mass ratio of the prepared TLMC samples.

Fig. $4 \mathrm{~b}$ Effect of rolling temperature on the percent decrease in thickness (sample \#1.) 


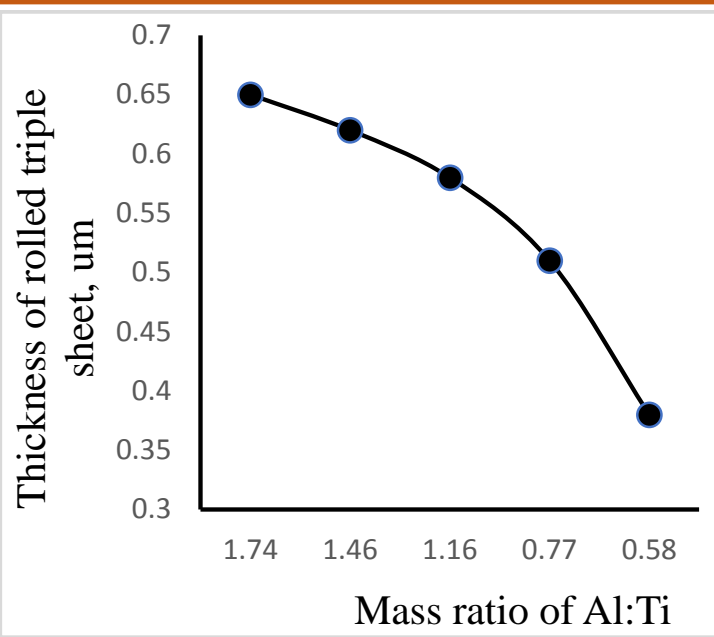

Fig. 5a Effect of Al:Ti mass ratio on the thickness of the roll bonded triple sheet at $550^{\circ} \mathrm{C}$ for $40 \mathrm{sec}$.

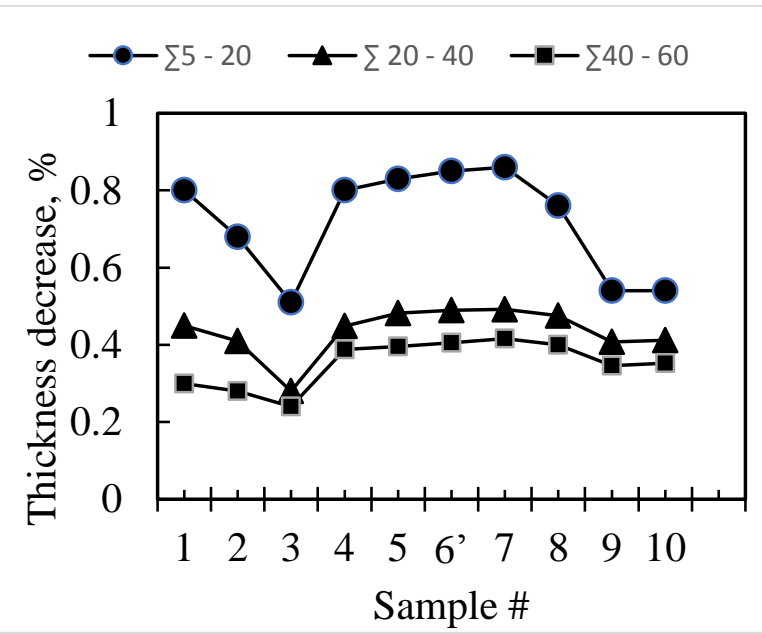

Fig. $5 b$ Effect of sample composition on the decrease in thickness of samples bonded at $550^{\circ} \mathrm{C}$ for $40 \mathrm{sec}$

Fig. 6a shows the density of the triple-layered sheet prepared with different thickness of titanium and constant thickness of aluminium at $0.2 \mathrm{~mm}$. It is seen that the density value increases slightly with the increase in the thickness of the titanium layer. Density attains a value of $2.53 \mathrm{~g} / \mathrm{cm}^{3}$ with samples having about $0.38 \mathrm{~mm}$ titanium in thickness. Fig. $6 \mathrm{~b}$ shows the effect of the global thickness of the prepared triple sheet sample by hot pressing the three materials having an equal thickness on the density value. It is seen that the density value displays the same trend as shown in Fig. $6 a$ provided that the value of the density is comparatively higher.
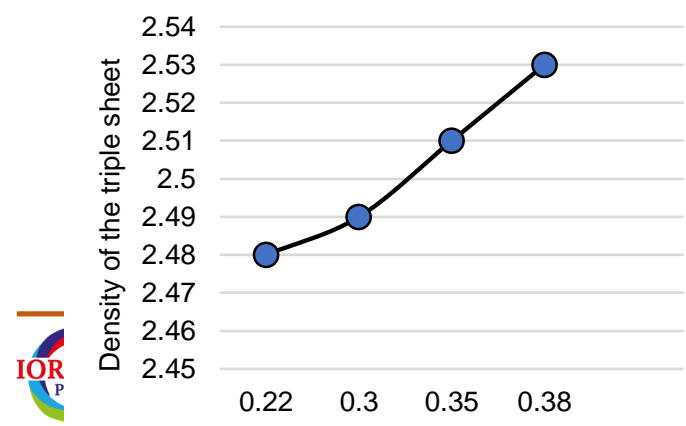

Figure $6 a$ The density of the triple-layered sheet having different thickness of aluminium and a constant thickness of titanium of $0.2 \mathrm{~mm}$

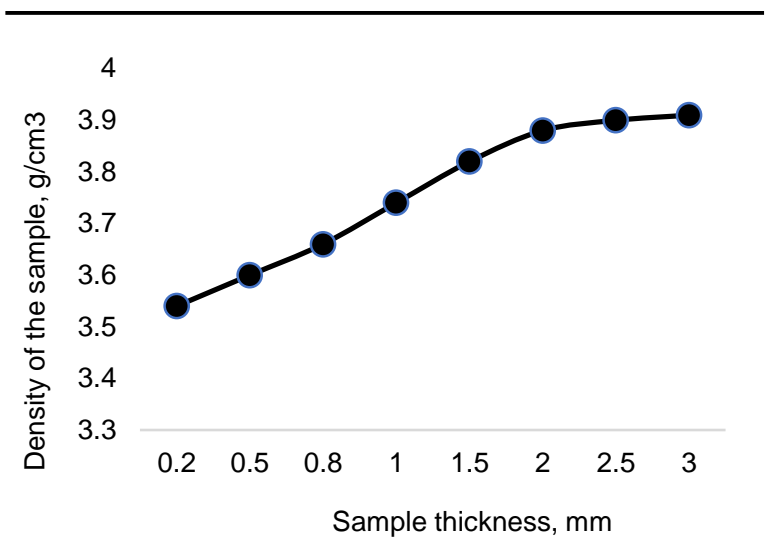

Figure $6 \mathrm{~b}$ Thickness of the prepared triple-layered AlPTFE/C-Ti samples

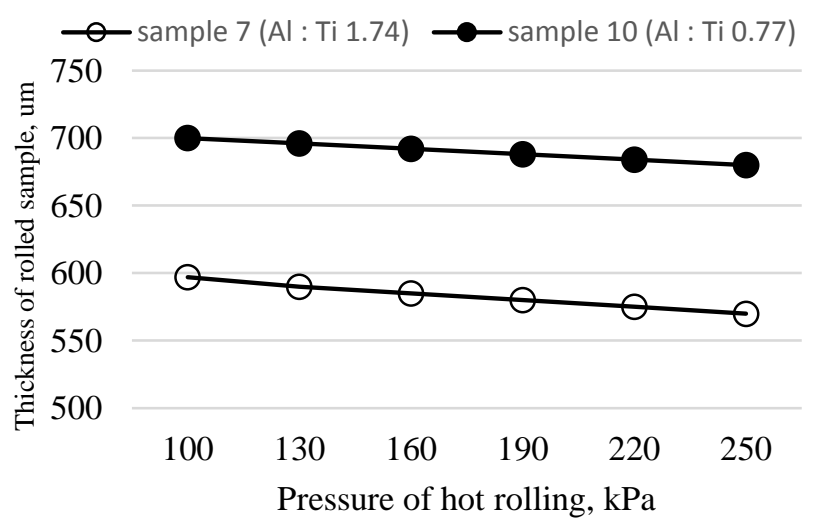

Figure 7 Effect of hot rolling pressure on the thickness of the rolled sample at $500^{\circ} \mathrm{C}$.

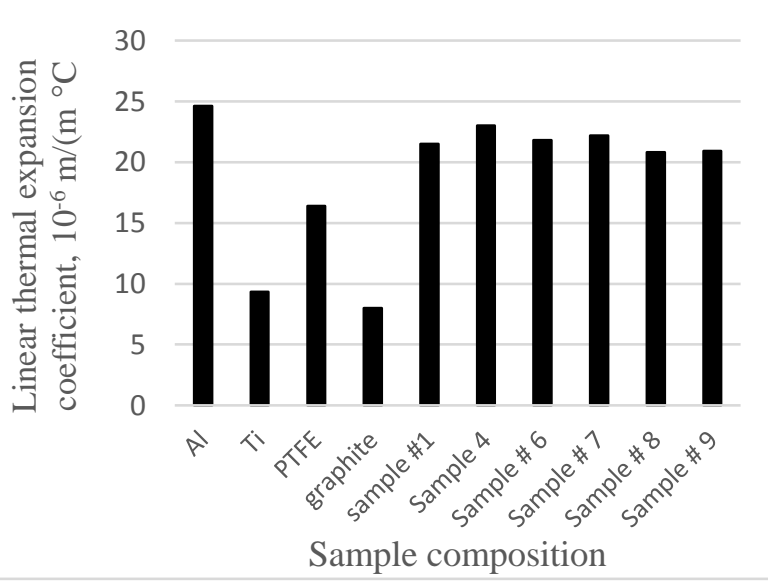

Fig 8 The linear thermal expansion coefficient (LTEC) of the prepared samples 
Fig 7 shows the effect of pressure of rolling at $500{ }^{\circ} \mathrm{C}$ on the rolled triple layered sheet with samples \# 7 and 10. It is seen that increasing the pressure of hot rolling linearly decreases the thickness of the sample.
Fig 8 shows the linear thermal expansion coefficient (LTEC) of the prepared samples. It is seen that the LTEC value increases in the order Al metal, samples having high Al content, titanium and graphite.

Table 6 Technical details of the finished triple-layered AI-C-Ti sheets

\begin{tabular}{|c|c|c|c|c|c|c|c|c|c|c|}
\hline \multirow[t]{2}{*}{ Sample \# } & \multicolumn{4}{|c|}{ Thickness, um } & \multicolumn{5}{|c|}{ Space separating layers $\mathrm{nm}$} & \multirow{2}{*}{$\begin{array}{l}\text { Density, } \\
\mathrm{g} / \mathrm{m}^{2}\end{array}$} \\
\hline & $\mathrm{Al}$ & PTFE/C & $\mathrm{Ti}$ & $\begin{array}{l}\text { Finished } \\
\text { sample }\end{array}$ & $\mathrm{Al} \mathrm{/}$ & C 1 & & $\mathrm{Ti}$ & $\begin{array}{l}\text { S } \\
\text { sample }\end{array}$ & \\
\hline $\begin{array}{l}\text { The density, } \\
\mathrm{g} / \mathrm{cm}^{3}\end{array}$ & 2.650 & 2.25 & 4.50 & Hypo-thetical & measured & & & & & \\
\hline 1 & 100 & 10 & 50 & 160 & 155 & 4.6 & 4 & 52 & 49.2 & 5.25 \\
\hline 2 & 200 & 50 & 100 & $350 \quad 340$ & & 4.6 & 4 & 52 & 49.2 & 7.75 \\
\hline 3 & 100 & 50 & 100 & $250 \quad 242$ & & 3.2 & 4 & 23.5 & 24 & 7.25 \\
\hline 4 & 200 & 50 & 200 & $\begin{array}{ll}450 \quad 440 \\
\end{array}$ & & 3.2 & 4 & 23.5 & 24 & 22.15 \\
\hline 5 & 300 & 50 & 200 & $\begin{array}{ll}550 \quad 540\end{array}$ & & 3.2 & 4 & 23.58 & 22 & 26.35 \\
\hline 6 & 500 & 50 & 500 & $1050 \quad 1035$ & & 3.0 & 4 & 21 & 18.5 & 39.5 \\
\hline 7 & $1 \mathrm{~mm}$ & 50 & 500 & 15501442 & & 3.0 & 4 & 13 & 12.5 & 57.2 \\
\hline $8 /$ & $2 \mathrm{~mm}$ & $1 \mathrm{~mm}$ & $\begin{array}{l}1 \\
\mathrm{~mm}\end{array}$ & $4 \mathrm{~mm} \quad 3.86 \mathrm{~mm}$ & & 3.0 & 4 & 11 & 10 & 114 \\
\hline 9 & $2 \mathrm{~mm}$ & $1 . \mathrm{mm}$ & $\begin{array}{l}2 \\
\mathrm{~mm}\end{array}$ & $5 \mathrm{~mm} \quad 4.85 \mathrm{~mm}$ & & 2.9 & 4 & 5 & 5 & 182 \\
\hline 10 & $3 \mathrm{~mm}$ & $1 \mathrm{~mm}$ & $\begin{array}{l}3 \\
\mathrm{~mm}\end{array}$ & $7 \mathrm{~mm} \quad 6.80 \mathrm{mn}$ & & 2.9 & & $\begin{array}{ll}44 \\
\end{array}$ & 3 & 208 \\
\hline
\end{tabular}

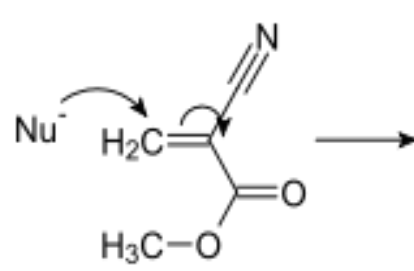<smiles>COC(=O)/C(C#N)=C\CCC#N</smiles><smiles>COC(=O)[C](C#N)CC(C#N)(C[14CH3])C(=O)OC</smiles>

Synthesis Polymerization of methyl 2-cyanoacrylate

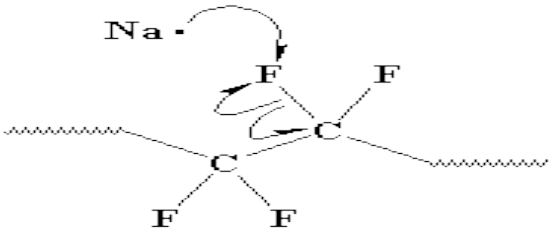

Table 6 shows the technical details of the finished samples of triple-layered Al-C-Ti sheets prepared by hot roll bonding technique.

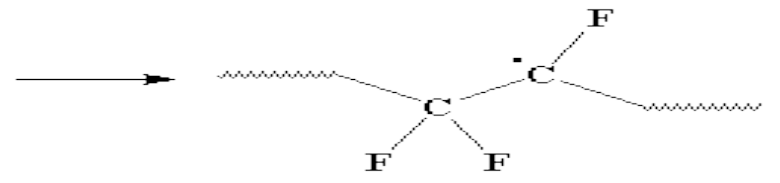

$+\operatorname{TaF}$

The cyanoacrylate adhesive is commercially known as super glue. The material is used to combine anything from metal to plastic and even human skin and frequently used in bonding the following:

1. Aerospace components

\section{Discussion}


2. Automotive subassemblies

3. Musical instruments

4. Appliance part assembly

5. Disposable medical device applications.

PTFE, it is an important material in the industry because of the following reasons.

a. It is a tough, flexible, non-resilient material.

b. is used in aircraft where high temperature resistance is required.

c. Has an average tensile strength.

d. Great thermal properties.

e. Excellent resistance to chemicals and passage of electric current.

f. PTFE is an outstanding insulator over a wide range of temperatures and frequency.

g. It is outstanding and chemically stable.

h. PTFE is insoluble in the organic solvents.

i. The PTFE polymer is a thermoplastic material. However and due to its high viscosity, it cannot be processed using conventional polymer processing techniques. Hence, PTFE is processed by cold shaping operation followed by heat treatment (sintering) during which the polymer particles fuse to form a solid molding.

Aluminium metal doesn't rust because a thin layer of a protective aluminium oxide forms on the surface of the metal. Upon cooling of the hot homogenized polymer poured on aluminium surface, the mix would microphase separate with the $\mathrm{OH}$ moiety concentrating on the metal surface and the carbon fluoride $\mathrm{CF}$ migrating away from it. The $\mathrm{H}$-bonds are stronger than Van Der Vaals interactions and the two metals are chemically bonded. The entropy of the bond case would be such that chains of CF remain imbedded in chains of $\mathrm{OH}$. It would be hard enough to get small molecules to crystallize quantitatively. Once the mixture set-up on the metal surface, heating would not return the coating to homogeneity.

The experimental protocol includes washing of the two metals (Aluminium and titanium) with oxygenated hot water. The aluminum and titanium would corrode and their own corrosion products would aid in binding to PTFE. A copolymer would probably work better than the blend that would indeed tend to phase separate. The polymer don't gain very much entropy on blending, so they don't blend unless there are strong enthalpic interactions. So PTFE would probably phase separate. Rough surfaces helps adhesive to stick to a surface because of the increase the working area of the two surfaces in contact. The interactive forces of PTFE are repulsive imparting roughening the surface will only increase the force of the repulsion between the two metal surfaces.

This aim of the present study is to prepare a composite aluminium-titanium-PTFE/C triple-layered metal sheet that would be regarded as a composite anisotropic and inhomogeneous material. Data of the periodic table shows that aluminium has an atomic weight of 26.9, and an atomic radius of $143.1 \mathrm{~nm}$. It is one of the most ductile and malleable metal. Aluminium is non-magnetic. The metals of aluminium and titanium are structured in fine particles or crystals as seen in Fig. 8. Fig. 8a show SEM images of the graphite-doped polymer emulsion (in perfluoro kerosene). Fig. $8 \mathrm{~b}$ is the SEM of Al particles while Fig.8c shows the SEM image of PTFE particles and Fig. 8d is the TEM of titanium .

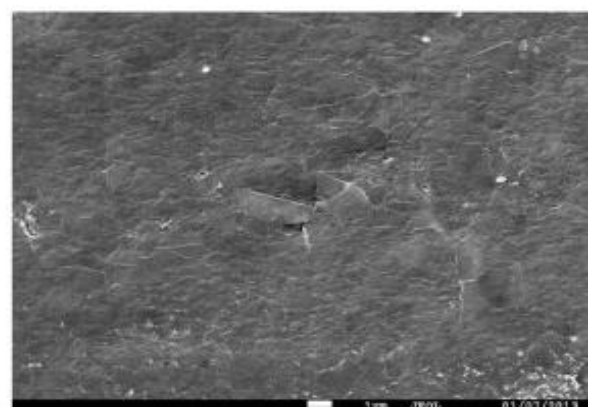

Fig 8a SEM images of the graphite-doped polymer emulsion in perfluoro kerosene.

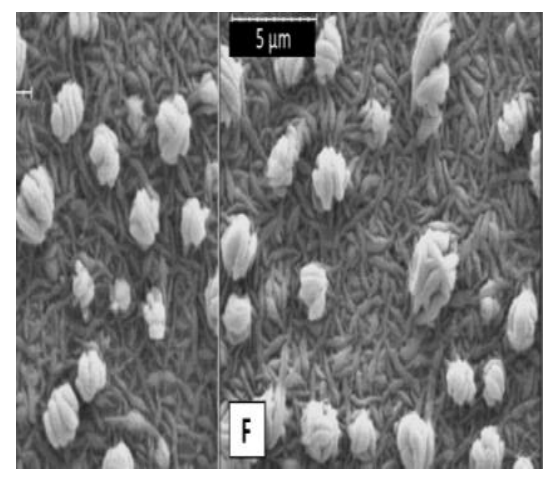

Fig. 8b SEM image of Al particles 


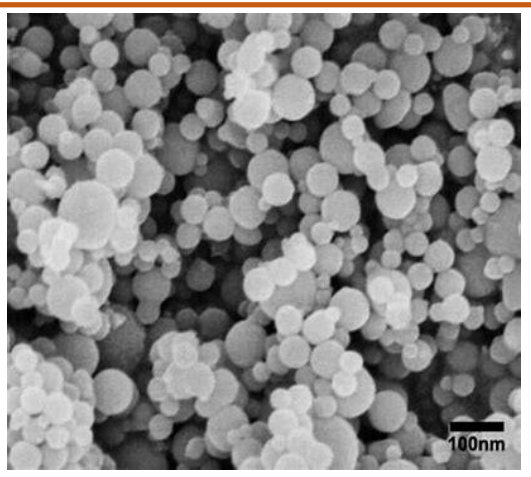

Figure $8 c$ image of PTFE

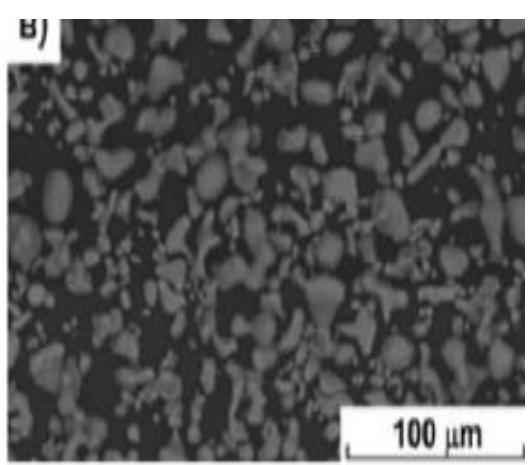

Figure 8d TEM of titanium

Titanium particles are small-sized crystals (24 $700 \mathrm{um}$ ) with larger extent as shown in Fig. 8d. Under the experimental conditions of this work, the prepared samples were hot roll bonded. The composite sheet is hot-rolled under 150-200 kPa. Pressing would cause a shape deformation of the spherically-shaped particles. Richard Collins [16] et al., for creating aircraft are highly recommended to be lighter. during this context, this work light aluminium, PTFE/graphite and titanium are used as a step to develop metals composite for possible use in an engineering application. The products of Al-PTFE/C-Ti triple sheet include aluminium because the classic metal and titanium which has good thermal resistance properties and could be a stiff material along with the PTFE polymer composite sheet. The latter could be a distinguished material with good resistance to corrosion and thermal chock.

he mechanism of shaping the triple-layered sheet would occur in a very similar thanks to the technology of shaping metal powders. The force of roll bonding would be uniformly distributed to the particles. a serious part of the roll bonding forces is retained at the intra-particle surface at certain active sites. Also, hot roll bonding of the 2 metal particles with the PTFE/graphite composite helps good binding the 2 metals using cyanoacrylate. Aluminium and titanium form a composite plate. The effect of roll bonding force on the apparent density value of the triple-layered AlPTFE/C-titanium may be understood

on the premise that the process involves the dislocation of the metal crystals with subsequent alignment to make solid metal with less porosity. Roll bonding aluminium to create smaller leaflet-shaped particles requires lower force while roll bonding of more hard titanium powder requires relatively higher force. Additives even have a job in determining the specified density. The friction force acting between metal particles resists movement of particles during rolling, therefore lubrication can reduce the specified roll bonding force and cause a more uniform distribution of particles during the method. Hot roll bonding decreases the spaces and gaps within the solid metal and density increases due to packing of the particles.

Density measurement given in Fig. 6 shows that the density of the prepared triple-layered AlPTFE/C-Ti sheet. The findings believe the model given above. Table 6 shows the properties of the finished triple-layered Al-PTFE/C-Ti sheets. it's seen that the sample before roll bonding features a very high porosity extent based on that is simply loose particles. The porosity decreases from $\approx 50$ you must 4 you bored with winding up the roll bonding force up to $150 \mathrm{k} \mathrm{Pa}$. In Fig. 7 results show that the pressure of hot rolling linearly decreases the thickness of the rolled samples given that the upper the Al: $\mathrm{Ti}$ ratio the lower the thickness becomes. In Fig. 8 the linear thermal coefficient property of the prepared Al-PTFE/C-Ti samples seems reasonable on basis of the collective thermal properties and therefore the weight ratio of the components forming the triple sheet. Measurements revealed that its thermal conductivity amounts to 46 $\mathrm{W} . / \mathrm{m}$. ${ }^{\circ} \mathrm{C}$ as compared to $135 \mathrm{~W} . / \mathrm{m} .{ }^{\circ} \mathrm{C}$ with aluminium, $1180 \mathrm{~W} . / \mathrm{m} .{ }^{\circ} \mathrm{C}$ with pitch-bounded graphite (for ab direction) and $15.6 \mathrm{~W} . / \mathrm{m}$. ${ }^{\circ} \mathrm{C}$ with titanium metal. Such figures would recommend the prepared triple-layered Al-PTFE/C-Ti for possible application within the engineering industry.

\section{Conclusion}

Results show that triple-layered AI-PTFE/C-Ti triple sheet prepared from aluminium, titanium and PTFE/graphite emulsion in perfluoro kerosene and using cyanoacrylate adhesive has been prepared. The effect of the experimental parameters that determine the characteristics of the end products was studied. The triple composite samples were chosen to collectively benefit the outstanding thermomechanical properties of each metal in these composites. Hot roll bonding and annealing of the samples were found highly recommended to yield a triple-layered AlPTFE/graphite-Ti sheet with outstanding physical and thermal properties. The weights $/ \mathrm{m}^{2}$ of the finished triple-layered AI-PTFE/C -Ti sheets are shown in table 
6. A triple sheet having variant physical and chemical properties was prepared after different time and pressure of hot rolling. Temperature help enhancing the metal reforming and bonding of the components. Thermal properties of the prepared Al-PTFE/C-Ti samples found reasonable. Measurements revealed that the thermal conductivity of the samples amounts to $46 \mathrm{~W} . / \mathrm{m} .{ }^{\circ} \mathrm{C}$ as compared to $135 \mathrm{~W} . / \mathrm{m} .{ }^{\circ} \mathrm{C}$ with aluminium, $1180 \mathrm{~W} . / \mathrm{m} .{ }^{\circ} \mathrm{C}$ with pitch-bounded graphite (for ab direction) and $15.6 \mathrm{~W} . / \mathrm{m} .{ }^{\circ} \mathrm{C}$ with titanium metal. The thermal linear expansion coefficient ranged from $20.910^{-6} \mathrm{~m} /\left(\mathrm{m}^{\circ} \mathrm{C}\right.$ to $2310^{-6} \mathrm{~m} /\left(\mathrm{m}^{\circ} \mathrm{C}\right.$. Such figures recommend the prepared triple-layered Al-PTFE/C-Ti for possible application in the engineering in general and aeronautics industry.

\section{References}

[1] S. Ajaya Kumar, A. Prabhu Kumar, B. Balu Naik, B. Ravi, A Review on the Mechanical Properties of Aluminum Based Metal Matrix Composites (MMCs), International Journal of Engineering Science Invention, 6 (2017) 12-15.

[2] L.E.G. Cambronero, E. Sánchez. J.M. RuizRoman, and J.M. Ruiz-Prieto, Mechanical characterization of AA7015 aluminium alloy reinforced with ceramics, Journal of Materials Processing Technology, 143-144 (2003) 378383.

https://doi.org/10.1016/S0924-0136(03)00424-2

[3] Sano, T., Srivatsan, T.S. (Eds.), Advanced Composites for Aerospace, Marine, and Land Applications II, Verlag: Springer International Publishing, 2016. https://doi.org/10.1007/978-3319-48141-8

[4] M.F. Ibrahim, H.R. Ammar, M. Samuel M.S.A. Soliman and F.H. Samuel, Mechanical properties and fracture of Al Aluminum 6092/B4C (boron carbide), Metals and Materials International, (23) (2017) 813-822.

[5] M.F. Ibrahim et al., Mechanical properties and fracture of $\mathrm{Al}-15$ vol.-\%B4C based metal matrix composites, International Journal of Cast Metal Research, 1 (2013) 7-14.

[6] B.S. Murty and S. Ranganathan, Chapter-1, A Brief History of Alloys and the Birth of HighEntropy Alloys, High Entropy Alloys 2014, Pages 1-12. https://doi.org/10.1016/B978-0-12-800251$\underline{3.00001-8}$

[7] Rana, Rajesh Purohit, and S. Das, Reviews on the alloying elements on the microstructure and mechanical properties of aluminium alloys and aluminium composites, International Journal of
Scientific and Research Publications, 2 (2012) 17.

[8] E. Magnello, A Century of Measurement: History of the National Physical Laboratory" HMSO 2000, p. 16. ISBN 0-9537868-1-1.

[9] R.A. Higgins, Part I: Applied Physical Metallurgy, Engineering Metallurgy (5th ed.). Hodder \& Stoughton. 2017, pp. 435-438.ISBN 0-34028524-9.

[10] C. A. F Clinton and R.A.S. Arnold, Machining Operations on the 'Bristol Mercury: Engine, Aero Engineering. Volume II, part 1. George Newnes. 1938, pp. 378-383.

[11] Permabond Engineering adhesives, Internet, 2020, PTFE adhesive - Industrial adhesives for bonding PTFE.

[12] V. Amigó. F. Romero, C.E. Da Costa and M.D. Salvador, Titanium and aluminium composites materials reinforced by $\mathrm{Ti}-\mathrm{Al}$ compounds, https://www.ipen.br/biblioteca/cd/ptech/2005/PDF 107 07.PDF.

[13] S. Rajakumar, and V. Balasubramanian, Diffusion bonding of titanium and AA 7075 aluminum alloy dissimilar joints-process modeling and optimization using desirability approach, The International Journal of Advanced Manufacturing Technology 86, (2016) 10951112. https://doi.org/10.1007/s00170-015-8223-7

[14] Miao Cao, Cui-ju Wanga un-kun Deng Kai-bo Ni Wei Liang and Yu-cheng Wu, Effect of Interface on Mechanical Properties of $\mathrm{Ti} / \mathrm{Al} / \mathrm{Mg} / \mathrm{Al} / \mathrm{Ti}$ Laminated Composites, Materials Research, 23 (2020). $\quad$ https://doi.org/10.1590/1980-5373-mr2019-0648

[15] Cheng Zhang, Shouxin Wang, Hanxue Qiao, Zejun Chen, Taiqian Mo, and Qing Liu Enhancing the Mechanical Properties of Hot Roll Bonded $\mathrm{Al} / \mathrm{Ti}$ Laminated Metal Composites (LMCs) by Pre-Bonding Diffusion Process, Metals 9 (2019) 795.

\section{https://doi.org/10.3390/met9070795}

[16] R. Collins, Out of the lab and into a plane: The emerging materials making aircraft lighter, Aircraft Interiors, 2018, online Jul 24 - IDTechEx

\section{Funding}

No funding was received for conducting this study. 


\section{Conflict of interest}

The Author has no conflicts of interest to declare that they are relevant to the content of this article

\section{About the License}

(C) The author 2021. The text of this article is open access and licensed under a Creative Commons Attribution 4.0 International License

\section{Cite this Article}

Mahmoud A. Rabah, Effect of Hot Rolling on the Intrinsic Properties of Aluminium-Titanium Bonded by PTFE/ C Cyanoacrylate, International Research Journal of Multidisciplinary Technovation, Vol 3, Iss 3 (2021) 12-22. DOI: https://doi.org/10.34256/irjmt2133 